\title{
Optimization of the Horizontal Sedimentation Tank to Predict Turbidity Removal Efficiency in Water Treatment Plant in Iraq
}

\author{
Ali. Hadi . Ghawi ${ }^{1}$, Yaser. Ibrahim. Jasem ${ }^{2}$ \\ ${ }^{1}$ Lecturer, Department of Civil Engineering, Engineering College, Al-Qadisiyah University. \\ ${ }^{2}$ Assistant Lecturer, Department of Chemical Engineering, Engineering College, University of \\ Diyala. \\ ghawi2000@yahoo.com ${ }^{1}$,yaser_ij@yahoo.com ${ }^{2}$
}

\begin{abstract}
The goal of this research was to design and evaluate the efficiency of horizontal sedimentation tank for water treatment using different position of baffles. Turbid water was treated using alum in the condition with and without baffle in the settling unit. Turbidity was the main determinant in assessing the effectiveness of the settling tank processes. Visualization and profiling research was done using a dye tracer. Samples were collection at different baffle horizontal and vertical height, different flow rates and turbidity with respect to time. Baffle position was found to be capable of increasing turbidity removal efficiency considerably in the settling tank by diminishing the surface loading rate and increasing the retention time. Simulation displayed that turbidity can be eliminated higher than $95 \%$. The type of water purified using optimum position of baffle was well below the WHO guideline for drinking water of $<5$ NTU.
\end{abstract}

Keywords: Baffle, Turbidity, Settling tank, Water treatment plant, Tracer.

Paper History: Received: (5/10/2016), Accepted: (12/12/2016)

\section{Introduction}

Water covers $70 \%$ of the Earth's surface, and despite that there is severe water dearth. Salt water, however, amounts to $97.5 \%$ and nearly $75 \%$ of the freshwater is frozen in ice caps. Consequently, more than one third of the world's population, that is 2.4 billion people, has no access to clean water. The issue of water - its quality and its quantity. To meet these goals water has to be treated properly [1]. As a result of atmospheric changes and the environment changes in the earth and water scarcity in the Middle East and increasing pollutants in the rivers, especially the Euphrates River, which led to a lack of efficiency of the water treatment plants require finding scientific solutions to deal carefully with the weather variables and increasing amount of pollutants. Sedimentation is one of the most common particle separation methods, although simple in principle, sedimentation tank still effective and essential in modern water and wastewater treatment. In water treatment, sedimentation tank usually aim at removing impurities, turbidity and color that produced by coagulation and flocculation [2].

Many factors can affect the performance and efficiency of water treatment, especially in the processing parameters is always fluctuating. For example, the decline turbidity parameters depend on the ability of combination treatment in coagulation, flocculation and sedimentation as well as the addition of coagulant [3].

Sedimentation tanks of various shapes and flow patterns are used for the separation of suspended solids in the treatment of water, sewage and industrial effluents. The principal configurations are rectangular tanks with flow from end to end. In spite of numerous studies carried out on model sedimentation tanks, there is still no agreed method by which results obtained on small models can be used to predict accurately the performance of full-scale tanks. The main reason for this is that it is impossible to apply the usual hydraulic scaling laws, based on Reynolds or Froude Numbers, simultaneously to the large-scale system of the tank, and to the very small-scale system of the settling particles. The disparity between these two systems is so great that devices such as the use of a different fluid, or particles of a different specific gravity, are impracticable. However, simple model tanks can be used to demonstrate qualitatively, and to some extent quantitatively, the effects of varied design (especially of inlets) on the hydraulic and sedimentation performance [3]. The Armfield Model Sedimentation Tank (Figure 1) in sanitary engineering lab in collage of engineering in $\mathrm{Al}$ Qadisiyah University in Iraq is designed to demonstrate these effects in order to deal with the problems of settling tank 
design and operation. The experiments can be designed to analyze dispersion or flow-through patterns by the use of a tracer, or to study the removal of suspension (turbidity).

The major of this work was to explore the use of a Model Sedimentation Tank to evaluate the efficiency of horizontal settling tank in the treatment of turbid surface water from a stream.

The aim of this study is to show the use, benefits, applicability and main possibilities of The Armfield Model Sedimentation Tank in water treatment technology with focus on sedimentation tank. It is powerful tool, whose potential has been practically untapped by the water industry. As awareness of this grows there can be little doubt that we shall be seeing much more of The Armfield Model Sedimentation Tank in the future. The aim also is to validate the model of the existing sedimentation tank which situated at the AlDiwaniyah water treatment plants, and improve water quality, and to propose the retrofitted models to increase efficiency of the tank.

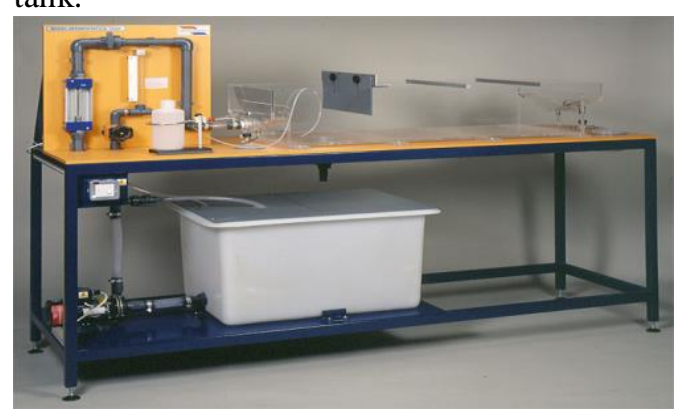

Figure 1: The Armfield Model Sedimentation Tank

\section{Materials and Methods}

Model Sedimentation Tank unit has been designed to demonstrate the hydraulic characteristics and settling efficiencies of a model settling basin. Although scale-up to industrial size sedimentation tanks is difficult, deductions relating to that can be according to how non-uniform flows occur and how these interact with the settling characteristics of particular suspensions. In this study a laboratory model of the sedimentation basin Model Sedimentation Tank imported from Armfield English Firm have been used to hold on the process of water from Al-Diwaniyah River to improve turbidity removal.

Raw water used in laboratory experiments bring from Al-Diwaniyah River near Water Treatment Plant (WATER PROJECT 6). It will conduct multiple experiments where change place and form of baffles at the entrance, middle and exit of sedimentation basins and which contribute to increasing the efficiency of deposition in addition to a change in the speed of water inside. Where Fluorescent dye has been added to show the behavior of sediment, suspended, dissolved and the hydraulic behavior of the sedimentation basin and then measure the efficiency of the sedimentation basins to increase the removal of turbidity.

In this research the results of study can improve the efficiency of the stages of conventional treatment (sedimentation, filtration and disinfection) and the water quality of Al-Diwaniya water treatment plant (WATER PROJECT 6) in the city of AlDiwaniya (One of the largest cities of AlQadisiyah governorate, Iraq. The number of beneficiaries from the station about 300 thousand people. It is one of the biggest stations in the city. It was constructed in 1982 .The design capacity of $6000 \mathrm{~m}^{3} / \mathrm{h}$. The station supplied with water from the Al-Diwaniya River as shown in Figure 2.

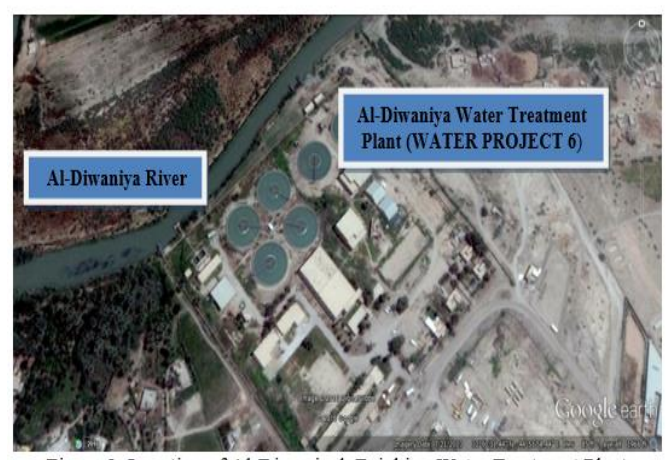

Figure 2: Location of Al-Diwaniyah Drinking Water Treatment Plant

The tentative study is done at Sanitary Engineering Laboratory Public Works Civil Engineering Department at college of Engineering Al-Qadisiyah University Iraq. Chemicals and equipments used in this work are outlined as follows:

\section{Preparation of Alum Coagulant :}

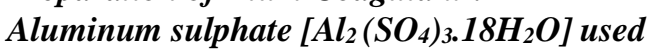

in this work was of industry grade. $1 \%$ solution concentration of alum was made by adding $1.0 \mathrm{~g}$ of alum in $100 \mathrm{~mL}$ distilled water. The alum was totally concentration in the water. A fresh solution was prepared daily [4].

\section{Sampling collection:}

The samples were collected for the examination of physical and chemical properties by the plastic cans $(20 \mathrm{~L})$. Samples were taken from the raw and treated water. The physical and chemical properties of the samples were conducted by the equipment available in the laboratories of Sanitary engineering lab in Collage of Engineering in Al-Qadisiyah University Al-Diwaniya /Iraq, as one sample every month. Turbidity was 
measured using a device (MARTINI Turbidity Meter), while the $\mathrm{pH}$ has been measured using a device (Multi-Parameter PCS Tester Tm 3s). Figures (3-4) describe the variation of physical and chemical characteristics of the raw and treated water with time.

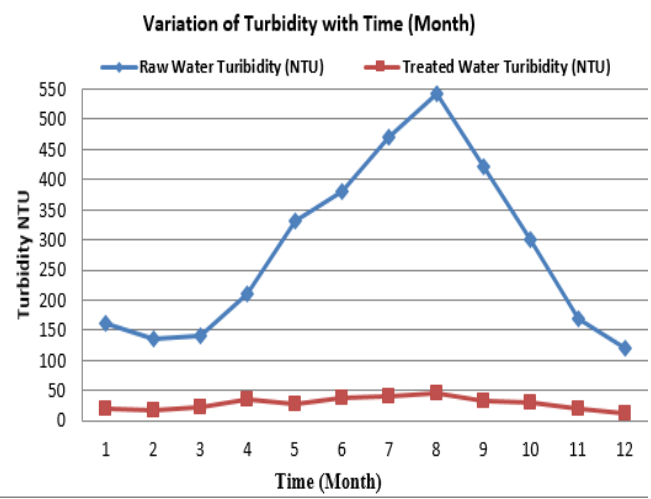

Figure 3: Variation of Turbidity with Time

(Month)

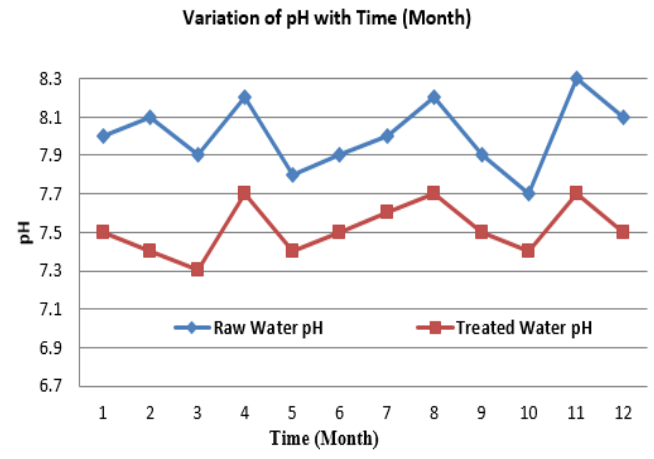

Figure 4: Variation of $\mathrm{pH}$ with Time (Month) Jar Test:

A Jar test apparatus type Lovibond and the river water samples (low, medium, and high turbidity from Al-Diwaniya River ) were used in this study to obtain the optimum coagulant dose for each experimental run. The turbidity for river water samples were 50, 100, and 500 for low, medium and high turbidity, respectively. A six paddle standard jar test with variable rotational speed and six $1000 \mathrm{~mm}$ jars was used .Every jar loaded with $500 \mathrm{ml}$ sample. The optimizations for alum were conducted using the jar test apparatus. The apparatus allowed six beakers to be agitated simultaneously. The beakers were filled with $500 \mathrm{ml}$ of synthetic turbid water and were agitated for $4 \mathrm{~min}$ at $100 \mathrm{rpm}$ (rapid mix) and $25 \mathrm{~min}$ at $40 \mathrm{rpm}$ (slow mix). This was followed by $30 \mathrm{~min}$ of sedimentation. After settling, $30 \mathrm{ml}$ of the sample was taken from the middle of each beaker using a pipette and placed in small beaker for further analysis [4].

\section{Experimental Work:}

The sedimentation process takes place in a horizontal rectangular sedimentation tank
(Armfield Model Sedimentation Tank height $1.55 \mathrm{~m}$, width - $1.90 \mathrm{~m}$, depth - $0.60 \mathrm{~m}$ ).

The effect of baffles on the performance of sedimentation tanks has been conducted. The performance of these tanks was directly investigated by the mean turbidity value measured from along the tank. The performance of sedimentation tanks is determined by outlet turbidity, which is the most important in determination of sedimentation tank performance. Finally, a best baffle configuration for a rectangular sedimentation tank was determined. In order to find the best baffle configuration, single baffle, with various heights and positions, were also investigated. The effects of baffles on velocity and turbidity concentration profiles along the tank were studied as well.

Raw water is taken from the Al-Diwaniya River and it is made to flow to the settling tank by way of flow meter. Raw water known turbidity value and flow is fed to the tank uniformly under an inlet weir. For hydraulic tracer and visualization studies, an precise dye injection system is supplied. A known volume of dye solution is pumped just prior to the intake into the settling tank [5].

Profiling is executed so as to study the flow patterns and turbulence of water while being pumped into the sedimentation tank using a dye to trace the pattern. This test is important to determine the suitable conditions for the sedimentation process in terms of the solution flow rate. After adjusting experimental devices and installing measuring facilities, the experiments are performed. The experimental program is divided into three major phases. In the first phase, the sedimentation process is studied in cases without baffle. In the second phase, a baffle is placed at $6 \mathrm{~cm}$ from the inlet and experiments are performed using $11 \mathrm{~cm}$ and $14 \mathrm{~cm}$ baffle heights. In the third phase, a baffle is placed at $14.5 \mathrm{~cm}$ from the inlet and experiments are performed using 11, and 14 $\mathrm{cm}$ baffle heights.

To ensure the quality and accuracy of the achieved data, each experiment is repeated several times under identical conditions. The flow rate of water is started with $5 \mathrm{~L} / \mathrm{min}$ and repeat the work with different flow rates of 8 $(\mathrm{L} / \mathrm{min})$ and $(12 \mathrm{~L} / \mathrm{min})$ at the same baffle specification.

\section{Result and Discussion:}

Tracer test:

After injecting the colouring with fluorescent, the veins in the tank may be observed. Figure 5 described graphically the observed ways with various flow rates and baffles position. Every variation in the flow rates has, however, a 
similar flow pattern, but velocity was fluctuating alongside the basin.

Figure 5a, shows strong surface current without baffle in Armfield Model Sedimentation Tank, particles bring by the surface current will flow out of the tank directly without enough time for detention, the flow direction move downward after reach the outlet side wall, then the downward flow transfer into bottom current with direction opposite to the surface current, thus generate the re-circulating current, the surface current will leads to short detention time, while bottom current will disturb stability of sludge layer at the tank bottom. Re-circulating current leads to dead zone in sedimentation tanks, if dead zone occupy volume of the sedimentation tank, effective volume of sedimentation tank will decrease, thus reduce sedimentation volume for suspended solids, on the other hand, recirculating current cause mixing, strong mixing may bring bottom settled particles back to surface and disturb stability of fluid inside sedimentation tank, so one major goal for sedimentation tank design is reduce the recirculating current [2].

Figure $5 b$, displayed the simulation result after installing a baffle with a $14.5 \mathrm{~cm}$ distance from the inlet and $14 \mathrm{~cm}$ height from bottom. The surface current seems to be improved with the baffle, although a new velocity zone appeared between baffle and outlet, the direct strong surface current still reduced dramatically, from Figure 5b, we could find the fluid move downward due to effect of baffle, a portion of fluid bypass the baffle and reach surface again, this is the reason for the velocity zone between baffle and outlet depicted in Figure 5b. It can be seen for this case, two recirculation zones exist. A small vortex in zone upstream and a large vortex in zone downstream were formed. Vortex zones decrease the effective size of the basins and the effective size for sedimentation process will be decreased and the suspended particles will not have sufficient space for deposition. Therefore, the increasing of the removal efficiency at basin with baffle at $6 \mathrm{~cm}$ from inlet and $14 \mathrm{~cm}$ height from bottom indicate that zones in this case are minimum. This means that decreasing the baffle installation distance from inlet from 14.5 to 6 $\mathrm{cm}$ leads to decrease of the height and extent of the vortex zones after the baffle position.

To avoid bypass flow around baffle, we ran the simulation with a $6 \mathrm{~cm}$ baffle rather than a 14.5 $\mathrm{cm}$ baffle and the results are given in Figure $5 \mathrm{~d}$, the velocity zone and bypass flow that appeared in Figure 5d have disappeared, means the fluid very close to "plug flow" situation. The lower rates of flow are always desirable; however, too low rates of flow ought to be avoided in settling tank.

The experimental work shows a better sedimentation when baffle at $6 \mathrm{~cm}$. This was concluded more efficient decrease in settling is seen at baffle at $6 \mathrm{~cm}$ than that at $14 \mathrm{~cm}$ height.

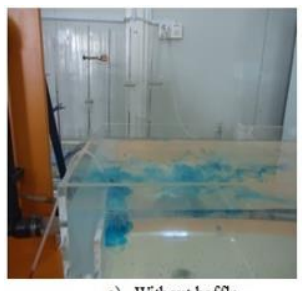

a) Without baffle

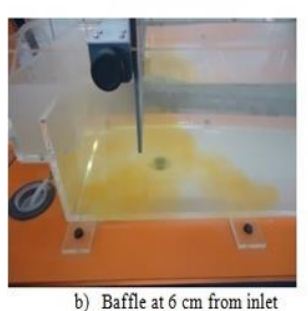

b) Baffle at $6 \mathrm{~cm}$ from inlet

Figure 5: Fluorescent dye test

\section{Turbidity Removal Efficiency:}

After obtaining the sedimentation behavior or characteristics of sediments and raw water, the optimum place of baffle which gave the minimum effluent turbidity i.e. maximum turbidity removal was determined for the various flow rates. The results are shown in Figures 6, and 7. As it can be seen that, the optimum place of baffle, which provided the highest turbidity removal with the optimized flow rate, is $6 \mathrm{~cm}$ from inlet with height $14 \mathrm{~cm}$ from bottom.

Armfield Model Sedimentation Tank flow rate Runs were carried out at three different flow rates, with values of 5,8 , and $12 \mathrm{ml} / \mathrm{min}$ and graph was plotted between inlet turbidity ( 500 NTU) versus outlet turbidity. The results are shown in Figures 8 . The results show that the flow rate $(8 \mathrm{ml} / \mathrm{min})$ produced the best effluent. Operation of the system at the maximum flow-rate $(12 \mathrm{ml} / \mathrm{min})$ resulted in a decrease the turbidity removal efficiency as seen in escalation of the effluent turbidity. The effluent turbidity can be seen to rise and the observation of the dense sludge zone cloud confirms this suggestion.

The results indicate that, the lab scale effluent turbidity $(<2.2 \mathrm{NTU})$ is way below the WHO drinking water standards (5 NTU). This shows that the sedimentation tank is feasible in pretreating water prior to filter and can be adapted and supported by contemporary scientific knowledge. Nevertheless, it should be noted that if the experimental results are somewhat representative of the potential operation of the system at full-scale, it may be suggested that the relatively low flow rates of the design does not allow for enough water to be treated per day. 


\section{Conclusion}

High turbidity water is a great challenge to water treatment works as it can be hard to remove. The pretreatment of high rate of turbidity water (>400 NTU) is a challenging issue that is touched upon in this study. A series of laboratory experiments are conducted to study the effect of height and position baffles on sedimentation tank performance. Results showed that turbidity removal is dependent on position and height the baffle and flow rate. As for the baffle spacing, a height of $14 \mathrm{~cm}$ from the bottom and $6 \mathrm{~cm}$ from inlet of the tank can be used for effective sedimentation. The highest turbidity removal efficiency with the optimized tank was $99.1 \%$ with the lowest at $95 \%$. The results of the present show that sedimentation tank is feasible in pre-treating high turbid water for further treatment. The flow rate of $81 / \mathrm{min}$ was acceptable because it achieved lowest sedimentation turbidity. The quality of water treated using optimum position of baffle was well below the WHO guideline for drinking water of $<5$ NTU.

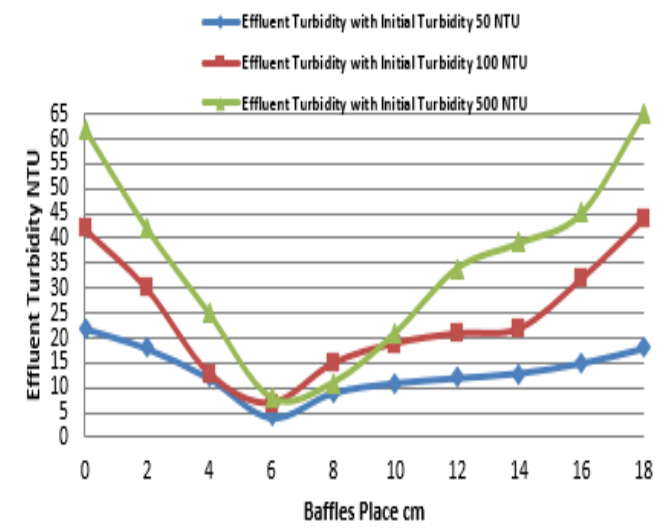

Figure 6: Optimum baffles place with height $11 \mathrm{~cm}$ to estimate effluent turbidity

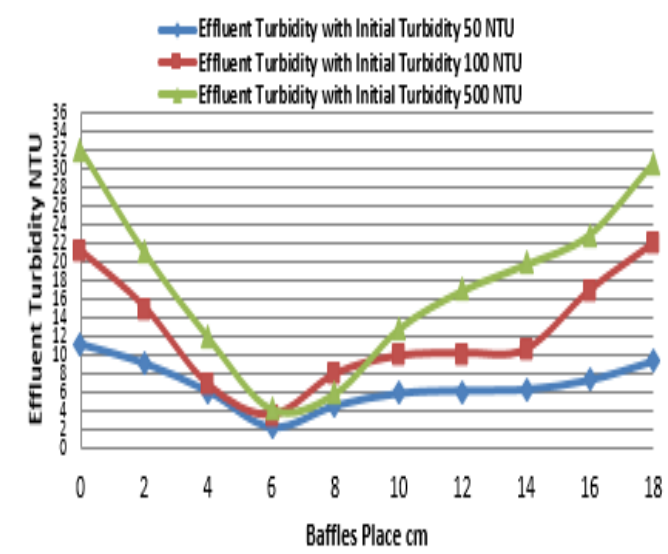

Figure 7: Optimum baffles place with height
$14 \mathrm{~cm}$ to estimate effluent turbidity

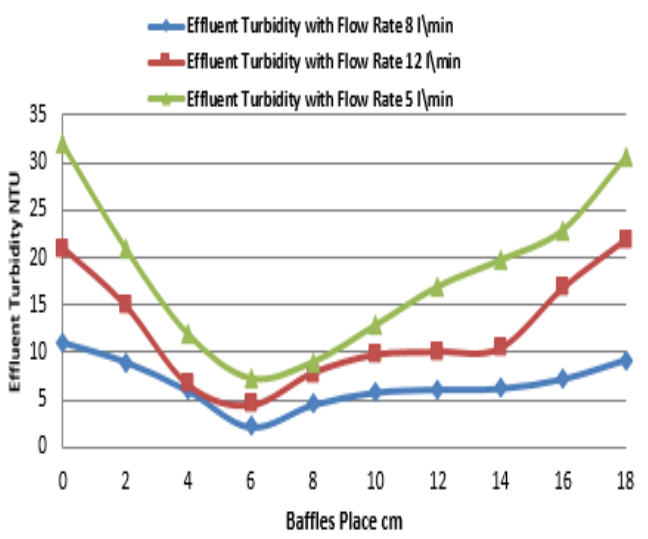

Figure 8: Optimum baffles place with height $14 \mathrm{~cm}$ to estimate effluent turbidity with different flow rate and initial turbidity 500 NTU

\section{References}

[1]. Shelestina O., and H. Ratnaweera, Optimization of the sedimentation tank with CFD simulation 2014, https://www.researchgate.net/.

[2]. Zhang D., Optimize sedimentation tank and lab flocculation unit by CFD, Master Thesis Norwegian University of Life Sciences Ås, Norway February 2014. [3]. Hidayah E. N., and O. Hendriyanto, Hydrodynamic model of sedimentation and disinfection to predict water quality in water treatment plant, International Journal of Science, Technology and Society; 2(4), (2014), 73-77 Published online June 20. (http://www.sciencepublishinggroup.com/j /ijsts) doi: 10.11648/j.ijsts.20140204.13

[4]. Katayon S.C, Megat M. N. and Abdullah A.G.L, "The effectiveness of Moringa Oleifera as primary coagulant in high-rate settling pilot scale water treatment plant" International Journal of Engineering and Technology, 3(2), (2006), 191-200.

[5]. Instruction Manual W7, Model Sedimentation Tank. Armfield: Water Treatment Processes, issue 15 March 2008. 